\title{
A RARE CASE OF ACQUIRED URINARY BLADDER DIVERTICULUM IN A BUFFALO CALF
}

\author{
R. V. SURESH KUMAR, P. VEENA, S. BHARATHI, L. SIVASUDHARSHAN \\ \& J. DEVARATHNAM \\ Department of Surgery and Radiology, College of Veterinary Science, \\ Proddatur (A.P.), India
}

\section{Summary}

Suresh Kumar, R. V., P. Veena, S. Bharathi, L. Sivasudharshan \& J. Devarathnam, 2015. A rare case of acquired urinary bladder diverticulum in a buffalo calf. Bulg. J. Vet. Med., 18, No 1, 91-94.

Urinary bladder diverticulum is an outpouching of urothelial mucosa through bladder muscular wall. The present paper reports one such rare accidental finding of acquired urinary bladder diverticulum in a buffalo calf and its surgical management. A 3-month-old male buffalo calf was presented with a history of not having passed urine for the previous 15 days but with no signs of bladder rupture. Physical and ultrasonographic examinations revealed intact and distended bladder. Medical management was unsuccessful and exploratory surgery revealed presence of large bladder diverticulum. Diverticulum was resected and tube cystotomy was performed. Animal had uneventful recovery without any complications.

Key words: buffalo calf, diverticulum, tube cystotomy, urinary bladder

Urinary bladder diverticula are congenital or acquired herniations of the bladder mucosa and submucosa through the detrusor muscle. Congenital diverticula are due to the weakness of urinary bladder musculature (Handa et al., 2001) and were reported in dogs (Remedios et al., 1994) and cats. Acquired diverticula are associated with trauma and secondary obstruction to urine outflow (Klaussner et al., 1983). Bladder diverticula arise within a trabeculated high pressure urinary bladder caused by bladder outlet obstruction (Omari \& Algazho, 2013). Most of urinary bladder diverticula are acquired and occur in males (Tamas et al., 2009). They usually have no symptoms and are incidentally discovered during examinations for other reasons. Congenital and acquired urinary bladder diverticula are uncommon abnormalities in buffalo calves. The present paper reports one such accidental finding of urinary bladder diverticulum in a buffalo calf with urinary obstruction and its surgical management.

A 3-month-old buffalo calf was presented to the Department of Surgery and Radiology, College of Veterinary Science, 
A rare case of acquired urinary bladder diverticulum in a buffalo calf

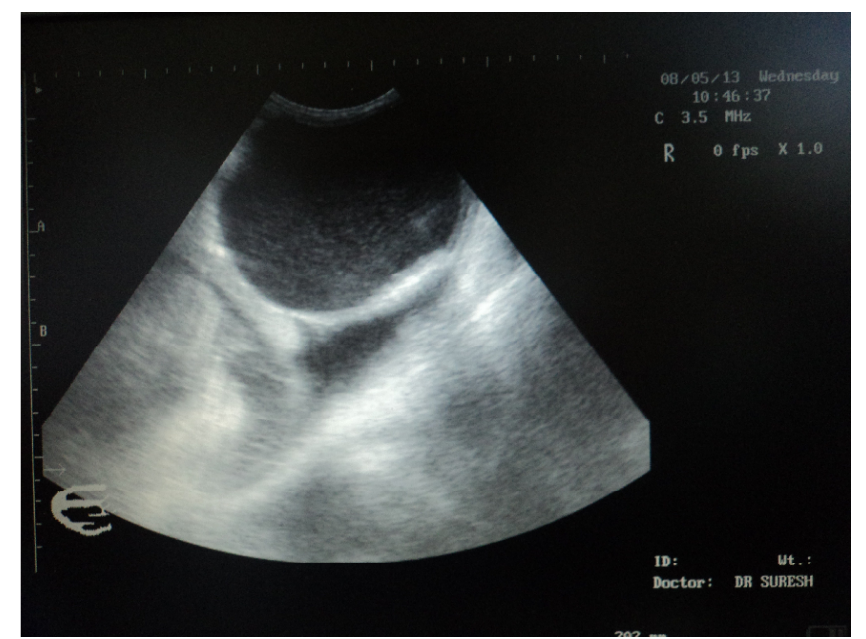

Fig. 1. Ultrasonogram of bladder showing a small anechoic area under the bladder.

Proddatur with the history of not having passed urine for the previous 15 days and being treated by a local veterinarian with antibiotics, anti-inflammatory drugs and appetite stimulants without any improvement in the condition. Anamnesis revealed that before complete obstruction, there were white sediments in the urine. On clinical examination restlessness, abdominal distension, increased pulse rate and congested mucous membranes were observed with no other signs of bladder rupture. Urinalysis revealed casts, epithelial cells, few RBC and proteins. Blood analysis was not performed.

Ultrasonographic examination revealed a small solitary anechoic area near the bladder which was connected to it (Fig. 1). Since the condition was refractory to medical treatment attempted by local veterinarian, surgical management was opted. Tube cystotomy was performed to arrive at confirmative diagnosis, and to relieve the condition. The animal was sedated using xylazine (Xylaxin, Indian Immunologicals) at $0.01 \mathrm{mg} / \mathrm{kg}$ and $2 \%$ lignocaine was used for local infiltration near the site of incision. Using para- median incision, bladder was exteriorised.

The diverticulum was clearly evident (Fig. 2). Uroliths were observed in the bladder (Fig. 3). Diverticulum was resected and the bladder was sutured in Cushing followed by Lembert pattern (Fig. 4). Retrograde urethral catheterisation failed due to presence of uroliths in the entire tract. Tube cystotomy was performed and the skin was sutured in routine manner (Fig. 5). Postoperatively animal was treated with ammonium chloride at $0.5 \mathrm{mg} / \mathrm{kg}$ along with enrofloxacin and meloxicam. Recovery status was obtained from the owner by telephone.

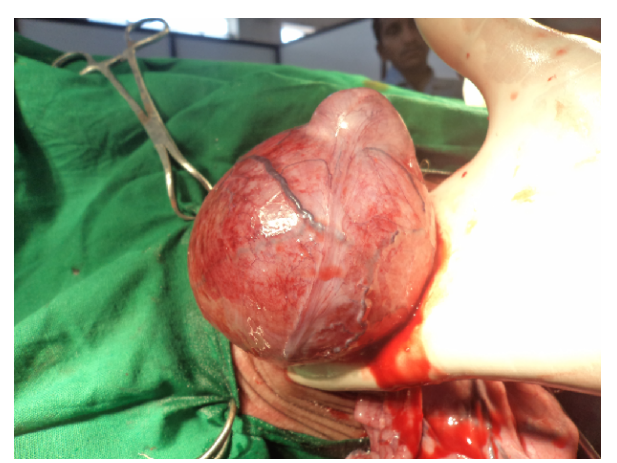

Fig. 2. Diverticulum on the bladder. 


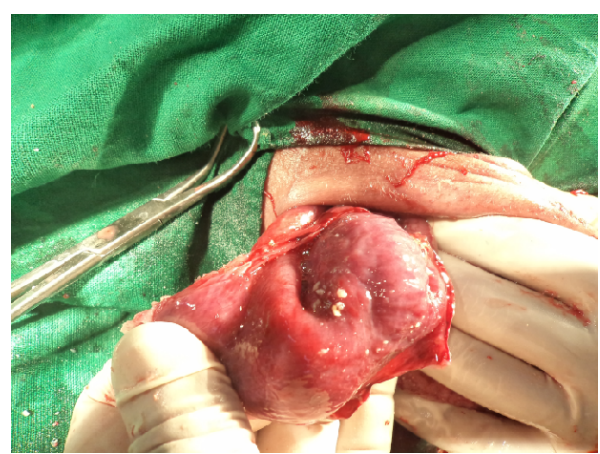

Fig. 3. Uroliths in the urinary bladder.

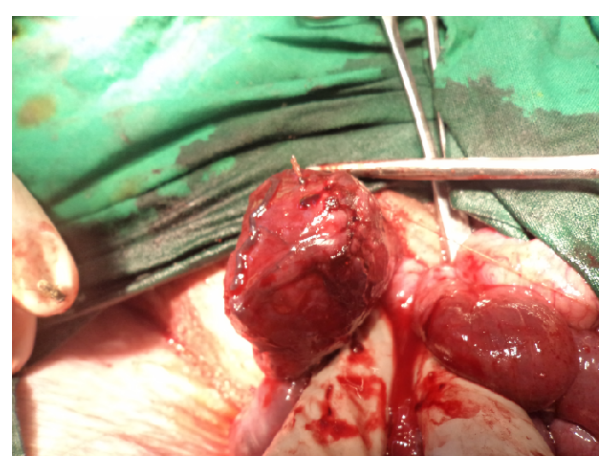

Fig. 4. Resection of diverticulum and suturing the bladder in continuous Lembert pattern.

In the present case report, buffalo calf did not show any symptoms of bladder diverticulum except for the signs of urinary obstruction. Urinary bladder diverticulum was accidentally detected during exploratory surgery. Increase in the intravesical pressure causes the urinary bladder mucosa to insinuate itself between muscle bundles of bladder resulting in development of a mucosal extravasational sac or saccule which further results in formation of diverticulum (Russell et al., 2000). Urinary bladder diverticulum in the present case could be attributable to chronic urinary obstruction due to urolithiasis which might be the cause for increase in intravesicular pressure. The management of urinary bladder diverticulum depends on the nature of lesion and its complications. Diverticulectomy and radical cystectomy were performed for management of urinary bladder diverticulum in case of humans (Meng et al., 2009). In the present case diverticulectomy was opted and urethral catheterisation was attempted. However due to presence of uroliths in the entire tract catheterization failed. Cystotomy tubes bypass urinary outflow obstructions as a alternative to urethral catheterisation (Dubey et

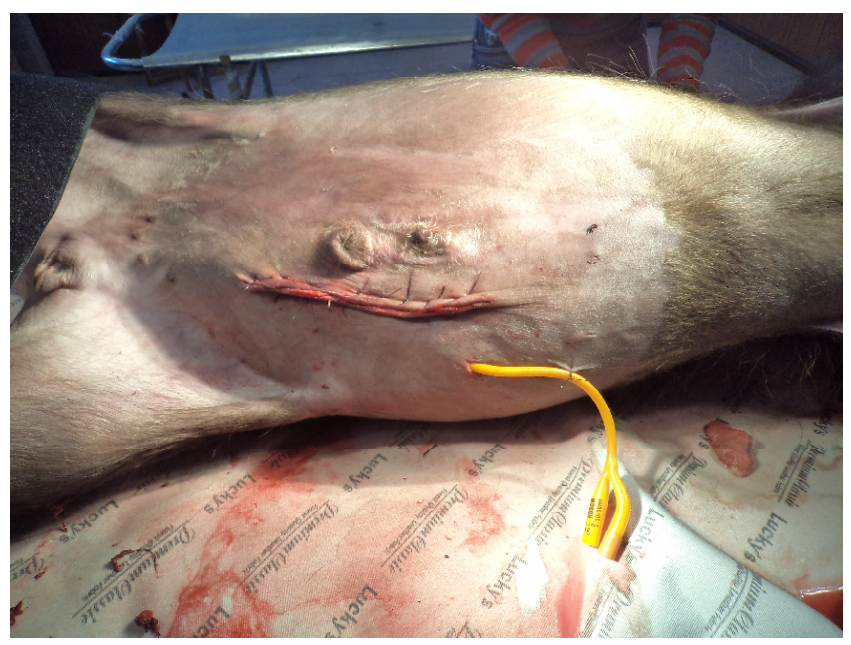

Fig. 5. Tube cystotomy performed in the buffalo calf. 
al., 2006). Hence in the present case tube cystotomy was performed after resection of urinary bladder diverticulum to divert urine flow which was followed by chemical dissolution of crystals with ammonium chloride. Tube cystotomy was performed in the following case since it avoids the difficult catheterisation procedure which involves urethrotomy at different levels of sigmoid flexure.

Urinary bladder diverticulum occurs due to chronic obstruction of urine outflow. Surgical resection of bladder diverticulum and tube cystotomy can be done to treat the condition.

\section{REFERENCES}

Dubey, A., K. Pratap, Amarpal, H. P. Aithal, P. Kinjavdekar, T. Singh \& M. C. Sharma, 2006. Tube Cystotomy and chemical dissolution of urethral calculi in goats. Indian Journal of Veterinary Surgery, 27, 98103.

Handa, S., G. Sethuraman, A. Mohan \& V. K. Sharma, 2001. Ehlers-Danlos syndrome with bladder diverticula. British Journal of dermatology, 144, 1084-1085.

Klausner, J. S., G. R. Johnston \& C. A. Osborne, 1983. Diverticula of the urinary bladder. In: Current Veterinary Therapy VIII, ed R. W. Kirk, WB Saunders, Toronto, pp. 1093-1095.

Meng, Z., J. Tan, F. Dong, Q. Jia \& F. Zhang, 2009. Demonstration of a congenital urine bladder diverticulum by $99 \mathrm{mTc}-\mathrm{MDP}$ $\mathrm{SPET} / \mathrm{CT}$ scan in a female with bone me- tastases. Hellenic Journal of Nuclear Medicine, 12, 276-278.

Omari, A. H. \& M. A. Algazho, 2013. Urinary bladder diverticulum as a content of femoral hernia: A case report and review of literature. World Journal of Emergency Surgery, 8, 20.

Remedios, A. M., D. M. Middleton, S. L. Myers, C. A. Outerbridge \& P. M. Arnold, 1994. Diverticula of the urinary bladder in a juvenile dog. Canadian Veterinary Journal, 35, 648-650.

Russell, R. C. G., N. S. Williams, \& C. J. K. Bulstrode, 2000. Bailey and Love's Short Practice of Surgery, $23^{\text {rd }}$ edition, Hodder Arnold, London, pp. 1218-1219.

Tamas, E. F., A. J. Stephenson, S. C. Campbell, D. K. Montague, D. C. Trusty \& D. E. Hansel, 2009. Histopathologic features and clinical outcomes in 71 cases of bladder diverticula. Archives of Pathology and Laboratory Medicine, 133, 791-796.

Paper received 24.03.2014; accepted for publication 13.06.2014

\section{Correspondence:}

J. Devarathnam

Department of Surgery and Radiology,

College of Veterinary Science,

Proddatur (A.P.), India

e-mail:drvictory84@gmail.com 